\title{
Editorial: Psychomotor symptomatology in psychiatric illnesses
}

\author{
Sebastian Walther ${ }^{1 *}$ and Manuel Morrens ${ }^{2}$ \\ ${ }^{1}$ University Hospital of Psychiatry, University of Bern, Bern, Switzerland, ${ }^{2}$ Collaborative Antwerp Psychiatric Research Institute, \\ University of Antwerp, Antwerp, Belgium
}

Keywords: schizophrenia, affective disorders, ADHD, Alzheimer's disease, autism spectrum disorders

\section{OPEN ACCESS}

Edited and reviewed by: Mihaly Hajos, Yale University School of Medicine,

*Correspondence:

Sebastian Walther walther@puk.unibe.ch

Specialty section:

This article was submitted to Schizophrenia, a section of the journal

Frontiers in Psychiatry

Received: 08 April 2015 Accepted: 17 May 2015

Published: 01 June 2015

Citation:

Walther S and Morrens M (2015) Editorial: Psychomotor symptomatology in psychiatric illnesses.

Front. Psychiatry 6:81. doi: 10.3389/fpsyt.2015.00081
In this research topic, we have gathered articles focusing on the psychomotor component of psychiatric disorders. Indeed, motor symptoms remain as an important dimension of psychopathology that can be assessed by objective means. Particularly, in major depressive disorder and schizophrenia, motor signs have been acknowledged from the very early descriptions (1-3). But, psychomotor abnormalities have also been demonstrated in other psychiatric disorders.

This research topic included nine original articles, four reviews, three opinion papers, and one mini-review. Catatonia has been subjected to two reviews $(4,5)$ and one investigation of its prevalence among acutely hospitalized patients (6). Neurological soft signs have been shown to occur in autism spectrum disorders (7), in Alzheimer's disease (8) and have been reviewed for their predictive validity in the course of schizophrenia (9). Fine motor tasks demonstrated that motor learning was preserved in schizophrenia despite cognitive and motor impairments $(10,11)$. In addition, psychomotor retardation was found in depressed elderly more than in elderly without depression (12). A neuroimaging study explored the cingulate motor area in motor retardation in major depression (13). The functional neuroanatomy of motor retardation in depression was also subjected to a mini-review (14). The topography of the cerebellum has been suggested as interesting focus of study to disentangle motor and cognitive functions in schizophrenia spectrum disorders (15). Two studies using actigraphy reported on gross motor activity in the course of schizophrenia $(16,17)$. Finally, Gawrilow and colleagues summarized the importance of motor activity in ADHD (18).

Currently, ambiguous terminology and definitions hamper research on psychomotor phenomena. In addition, some studies focus exclusively on single signs probably missing the complete picture. Therefore, we have tried to put forward a systematic approach to study psychomotor phenomena in psychotic disorders (19). In addition, van Harten and colleagues have proposed to consider movement disorders as non-mental signs of psychotic disorders just as psychiatric symptoms are classified as non-motor signs in idiopathic movement disorders (20).

One example of ongoing debate is the current discussion on the catatonia syndrome. Depending on the criteria applied, prevalence rates differ substantially $(6,21,22)$, challenging the specificity of assessment methods. Despite the fact that the syndrome is quite remarkable, there is not much of a common ground in the literature as to what catatonia should be defined as. Clearly, this ambiguity of definitions has contributed to the scarcity of descriptive and interventional studies in the catatonia syndrome.

Another important field of research is the outcome of interventions in motor symptoms. Further research needs to clarify whether the motor dimension in psychiatric disorders is properly ameliorated by treating the underlying disorder or whether specific therapeutic options are required. The former would call for generalized therapies in depression, schizophrenia, or autism. The latter would instead require searching for new therapeutic targets, such as in movement 
disorders known in neurology. Clearly defined psychomotor disturbances may benefit from deep brain stimulation of the subthalamic nucleus (23), pedunculopontine nucleus (24), or other targets such as the reward system (25). Likewise, non-invasive brain stimulation may become a treatment option in those psychomotor disturbances related to dysfunctions in cortical motor areas.

\section{References}

1. Sobin C, Sackeim HA. Psychomotor symptoms of depression. Am J Psychiatry (1997) 154(1):4-17. doi:10.1176/ajp.154.1.4

2. Walther S, Strik W. Motor symptoms and schizophrenia. Neuropsychobiology (2012) 66(2):77-92. doi:10.1159/000339456

3. Morrens M, Hulstijn W, Sabbe B. Psychomotor slowing in schizophrenia. Schizophr Bull (33) (4):1038-53. doi:10.1093/schbul/sbl051

4. Dhossche DM. Decalogue of catatonia in autism spectrum disorders. Front Psychiatry (2014) 5:157. doi:10.3389/fpsyt.2014.00157

5. Sienaert P, Dhossche DM, Vancampfort D, De Hert M, Gazdag G. A clinical review of the treatment of catatonia. Front Psychiatry (2014) 5:181. doi:10.3389/ fpsyt.2014.00181

6. Stuivenga M, Morrens M. Prevalence of the catatonic syndrome in an acute inpatient sample. Front Psychiatry (2014) 5:174. doi:10.3389/fpsyt.2014.00174

7. Hirjak D, Wolf RC, Koch SC, Mehl L, Kelbel JK, Kubera KM, et al. Neurological abnormalities in recent-onset schizophrenia and Asperger-syndrome. Front Psychiatry (2014) 5:91. doi:10.3389/fpsyt.2014.00091

8. Urbanowitsch N, Degen C, Toro P, Schroder J. Neurological soft signs in aging, mild cognitive impairment, and Alzheimer's disease - the impact of cognitive decline and cognitive reserve. Front Psychiatry (2015) 6:12. doi:10.3389/fpsyt. 2015.00012

9. Bachmann S, Degen C, Geider FJ, Schroder J. Neurological soft signs in the clinical course of schizophrenia. Front Psychiatry (2014) 5:185. doi:10.3389/ fpsyt.2014.00185

10. De Picker LJ, Cornelis C, Hulstijn W, Dumont G, Fransen E, Timmers M, et al. Stable schizophrenia patients learn equally well as age-matched controls and better than elderly controls in two sensorimotor rotary pursuit tasks. Front Psychiatry (2014) 5:165. doi:10.3389/fpsyt.2014.00165

11. Cornelis C, De Picker LJ, Hulstijn W, Dumont G, Timmers M, Janssens L, et al. Preserved learning during the Symbol Digit Substitution Test in patients with schizophrenia, age-matched controls and elderly. Front Psychiatry (2014) 5:189. doi:10.3389/fpsyt.2014.00189

12. Beheydt LL, Schrijvers D, Docx L, Bouckaert F, Hulstijn W, Sabbe BG. Psychomotor retardation in untreated depressed elderly. Front Psychiatry (2014) 5:196. doi:10.3389/fpsyt.2014.00196

13. Liberg B, Klauser P, Harding IH, Adler M, Rahm C, Lundberg J, et al. Functional and structural alterations in the cingulate motor area relate to decreased frontostriatal coupling in major depressive disorder with psychomotor disturbances. Front Psychiatry (2014) 5:176. doi:10.3389/fpsyt.2014.00176

14. Liberg B, Rahm C. The functional anatomy of psychomotor disturbances in major depressive disorder. Front Psychiatry (2015) 6:34. doi:10.3389/fpsyt.2015. 00034

15. Bernard JA, Mittal VA. Cerebellar-motor dysfunction in schizophrenia and psychosis-risk: the importance of regional cerebellar analysis approaches. Front Psychiatry (2014) 5:160. doi:10.3389/fpsyt.2014.00160
Taken together, clarified terminology, increased awareness, and improved assessment methods will help psychomotor symptoms to become an important objective dimension of psychopathology that is informative on underlying neuropathology and longitudinal course. These transitions in psychiatric assessment will also allow for more specialized interventions for psychomotor symptoms.

16. Walther S, Stegmayer K, Horn H, Razavi N, Müller TJ, Strik W. Physical activity in schizophrenia is higher in the first episode than in subsequent ones. Front Psychiatry (2014) 5:191. doi:10.3389/fpsyt.2014.00191

17. Walther S, Stegmayer K, Horn H, Rampa L, Razavi N, Muller TJ, et al. The longitudinal course of gross motor activity in schizophrenia - within and between episodes. Front Psychiatry (2015) 6:10. doi:10.3389/fpsyt.2015. 00010

18. Gawrilow C, Kuhnhausen J, Schmid J, Stadler G. Hyperactivity and motoric activity in ADHD: characterization, assessment, and intervention. Front Psychiatry (2014) 5:171. doi:10.3389/fpsyt.2014.00171

19. Morrens M, Docx L, Walther S. Beyond boundaries: in search of an integrative view on motor symptoms in schizophrenia. Front Psychiatry (2014) 5:145. doi:10.3389/fpsyt.2014.00145

20. van Harten PN, Backker R, Mentzel C, Tijssen M, Tenback DE. Movement disorders and psychosis, a complex marriage. Front Psychiatry (2014) 5:190. doi:10.3389/fpsyt.2014.00190

21. Wilson JE, Niu K, Nicolson SE, Levine SZ, Heckers S. The diagnostic criteria and structure of catatonia. Schizophr Res (2015) 164(1-3):256-62. doi:10.1016/j.schres.2014.12.036

22. Jaimes-Albornoz W, Serra-Mestres J. Prevalence and clinical correlations of catatonia in older adults referred to a liaison psychiatry service in a general hospital. Gen Hosp Psychiatry (2013) 35(5):512-6. doi:10.1016/j.genhosppsych. 2013.04.009

23. Castrioto A, Lhommee E, Moro E, Krack P. Mood and behavioural effects of subthalamic stimulation in Parkinson's disease. Lancet Neurol (2014) 13(3):287-305. doi:10.1016/S1474-4422(13)70294-1

24. Morita H, Hass CJ, Moro E, Sudhyadhom A, Kumar R, Okun MS. Pedunculopontine nucleus stimulation: where are we now and what needs to be done to move the field forward? Front Neurol (2014) 5:243. doi:10.3389/fneur.2014. 00243

25. Schlaepfer TE, Bewernick BH, Kayser S, Hurlemann R, Coenen VA. Deep brain stimulation of the human reward system for major depression - rationale, outcomes and outlook. Neuropsychopharmacology (2014) 39(6):1303-14 doi:10.1038/npp.2014.28

Conflict of Interest Statement: The authors declare that the research was conducted in the absence of any commercial or financial relationships that could be construed as a potential conflict of interest.

Copyright (C) 2015 Walther and Morrens. This is an open-access article distributed under the terms of the Creative Commons Attribution License (CC BY). The use, distribution or reproduction in other forums is permitted, provided the original author(s) or licensor are credited and that the original publication in this journal is cited, in accordance with accepted academic practice. No use, distribution or reproduction is permitted which does not comply with these terms. 